\title{
BMJ Open Evaluating the effectiveness of the NHS Health Check programme in South England: a quasi-randomised controlled trial
}

\author{
Oliver Kennedy, ${ }^{1}$ Fangzhong Su, ${ }^{1}$ Robert Pears, ${ }^{2}$ Emily Walmsley, ${ }^{1}$ Paul Roderick ${ }^{1}$
}

To cite: Kennedy 0, Su F, Pears R, et al. Evaluating the effectiveness of the NHS Health Check programme in South England: a quasi-randomised controlled trial. BMJ Open 2019;9:e029420. doi:10.1136/ bmjopen-2019-029420

- Prepublication history and additional material for this paper are available online. To view these files, please visit the journal online (http://dx.doi. org/10.1136bmjopen-2019029420).

Received 25 January 2019 Revised 12 August 2019 Accepted 14 August 2019

\section{Check for updates}

(c) Author(s) (or their employer(s)) 2019. Re-use permitted under CC BY-NC. No commercial re-use. See rights and permissions. Published by BMJ.

${ }^{1}$ Faculty of Medicine, University of Southampton, Southampton, UK

${ }^{2}$ Public Health Directorate, Hampshire County Council, Hampshire, UK

Correspondence to Dr Oliver Kennedy: ok4g13@soton.ac.uk

\section{ABSTRACT}

Objective To evaluate uptake, risk factor detection and management from the National Health Service (NHS) Health Check $(\mathrm{HC})$.

Design This is a quasi-randomised controlled trial where participants were allocated to five cohorts based on birth year. Four cohorts were invited for an NHS HC between April 2011 and March 2015.

Setting 151 general practices in Hampshire, England, UK. Participants 366005 participants born 1 April 1940-31 March 1976 eligible for an NHS HC.

Intervention NHS HC invitation.

Main outcome measures $\mathrm{HC}$ attendance and absolute percentage changes and ORs of (1) detecting cardiovascular disease (CVD) 10-year risk $>10 \%$ and $>20 \%$, smokers, and total cholesterol (TC) $>5.5 \mathrm{mmol} / \mathrm{L}$ and $>7.5 \mathrm{mmol} / \mathrm{L}$; (2) diagnosing hypertension, type 2 diabetes mellitus, chronic kidney disease (CKD) and atrial fibrillation (AF); and (3) new interventions with statins, antihypertensives, antiglycaemics and nicotine replacement therapy (NRT).

Results $\mathrm{HC}$ attendance rose from $12 \%$ to $30 \%$ between 2011/2012 and 2014/2015 ( $p<0.001$ ). HC invitation increased detection of CVD risk $>10 \%(2.0 \%-3.6$, $\mathrm{p}<0.001)$ and $>20 \%(0.1 \%-0.6 \%, p<0.001-0.392)$, TC $>5.5 \mathrm{mmol} / \mathrm{L}(4.1 \%-7.0 \%, \mathrm{p}<0.001)$ and $>7.5 \mathrm{mmol} / \mathrm{L}$ $(0.3 \%-0.4 \% \mathrm{p}<0.001)$, hypertension $(0.3 \%-0.6 \%$, $\mathrm{p}<0.001-0.003)$, and interventions with statins $(0.2 \%-0.9 \%, p<0.001-0.017)$ and antihypertensives $(0.1 \%-0.6 \%, p<0.001-0.205)$. There were no consistent differences in detection of smokers, NRT, or diabetes, AF or CKD. Multivariate analyses showed associations between $\mathrm{HC}$ invitation and detecting CVD risk $>10 \%$ (OR $8.01,95 \% \mathrm{Cl} 7.34$ to 8.73$)$ and $>20 \%(5.86,4.83$ to 7.10$)$, TC $>5.5 \mathrm{mmol} / \mathrm{L}(3.72,3.57$ to 3.89$)$ and $>7.5 \mathrm{mmol} / \mathrm{L}$ $(2.89,2.46$ to 3.38$)$, and diagnoses of hypertension $(1.33,1.20$ to 1.47$)$ and diabetes $(1.34,1.12$ to 1.61$)$. OR of CVD risk $>10 \%$ plus statin and $>20 \%$ plus statin, respectively, was 2.90 (2.36 to 3.57 ) and 2.60 (1.92 to 3.52), and for hypertension plus antihypertensive was 1.33 (1.18 to 1.50). There were no associations with AF, CKD, antiglycaemics or NRT. Detection of several risk factors varied inversely by deprivation.

Conclusions $\mathrm{HC}$ invitation increased detection of cardiovascular risk factors, but corresponding increases in evidence-based interventions were modest.

\section{Strengths and limitations of this study}

- This is the first study to investigate the outcomes associated with invitation for a National Health Service Health Check using a quasi-randomised method together with an intention-to-treat analysis.

- This study included a large population of 366005 participants in a mixture of urban, semiurban and rural settings.

- Invitation for a Health Check increased detection of cardiovascular risk factors, but this translated into only modest increases in evidence-based interventions.

- The follow-up of 6 months to 3.5 years limited the assessment of patient-relevant outcomes (eg, incident cardiovascular disease).

- There was insufficient information to consider outcomes related to alcohol consumption and diet.

\section{INTRODUCTION}

Cardiovascular disease (CVD) is a significant cause of mortality and morbidity worldwide, ${ }^{1}$ and results in substantial global healthcare expenditure. $^{2}$ In 2009, the National Health Service (NHS) in England began a Health Check (HC) programme with the intention of identifying and managing individuals at higher risk of CVD or related conditions, such as diabetes mellitus and kidney disease, and preventing such conditions. This is similar to national programmes in other countries including Canada ${ }^{3}$ and USA. ${ }^{4}$ Modelling by the UK Department of Health suggested that the NHS HC programme could prevent 1600 strokes and heart attacks each year, although the modelling assumptions, particularly with regard to uptake, may have overestimated effectiveness. ${ }^{5}$ More recent estimation of the health benefits from microsimulation modelling using existing programme data suggests that the NHS HC programme results in approximately 300 fewer deaths and 1000 people living free from disease (ischaemic 
heart disease, stroke, dementia and lung cancer) each year in England. ${ }^{6}$

Patients who are eligible to participate in the NHS HC programme are invited for HCs every 5 years. Patients are eligible if they are aged $40-74$ and have no known CVD, diabetes, kidney disease or previous treatment with statins. The HC itself is performed in primary care, largely in general practice (GP), and comprises an assessment of smoking status, diet, exercise, family history and more recently alcohol intake. Measurements are taken of body mass index (BMI), waist circumference, blood pressure (BP) and cholesterol, and a 10-year CVD risk score is calculated. Patients with systolic BP (SBP) or diastolic BP (DBP) $\geq 140 \mathrm{~mm} \mathrm{Hg}$ or $90 \mathrm{~mm} \mathrm{Hg}$, respectively, have additional blood tests to measure kidney function. If impaired kidney function is detected, that is, an estimated glomerular filtration rate $<60 \mathrm{~mL} / \mathrm{min} / 1.73 \mathrm{~m}^{2}$, the blood test is repeated within 2 weeks to confirm a diagnosis of chronic kidney disease $(\mathrm{CKD}){ }^{7}$ Any $\mathrm{HC}$ attendee with BMI $\geq 30 \mathrm{~kg} / \mathrm{m}^{2}\left(\geq 25 \mathrm{~kg} / \mathrm{m}^{2}\right.$ in non-white ethnic groups) or SBP or DBP above $\geq 140 \mathrm{~mm} \mathrm{Hg}$ or $90 \mathrm{~mm} \mathrm{Hg}$, respectively, is also screened for type 2 diabetes mellitus by measuring glycated haemoglobin (HbA1c) or fasting glucose. If CVD risk factors are newly identified or conditions newly diagnosed during the HC, patients are offered appropriate management, including lifestyle advice, treatments and referrals to local services.

The HC programme has been contentious from its inception. There have been concerns of a lack of proven effectiveness to justify the yearly expenditure, ${ }^{8}$ which is thought to be around $£ 450$ million. ${ }^{9}$ A systematic review of randomised controlled trials found that general health checks provide no overall reduction in CVD or cancer mortality, only an increase in risk factor recording and diagnoses. ${ }^{10}$ The initial implementation of the NHS HC programme suffered early problems, such as low uptake, ${ }^{11}$ variable implementation, ${ }^{12}$ and poor understanding of the aims and purpose of the $\mathrm{HC}$ among some invitees. ${ }^{13} \mathrm{In}$ addition, there were concerns about inequitable distribution of the $\mathrm{HC}$ and a resultant widening of health inequalities. ${ }^{9}$ Proponents of the NHS HC programme argue that existing randomised trials, the most recent of which started in 1999, are not representative of more effective modern HCs and intervention strategies. ${ }^{14}$ In addition, since the early years, participation has increased, with a 2018 study reporting that $48.2 \%$ of those invited for an HC have now attended. ${ }^{15}$ Strategies have also increased uptake among some deprived and ethnic minority populations to or above the average. ${ }^{16}$

A number of studies have evaluated the effectiveness of the NHS HC programme. ${ }^{16}{ }^{17} \mathrm{HC}$ attendance has been associated with increased CVD risk factor recording, detection of hypercholesterolaemia and hypertension, and increased prescribing of statins comparing attendees and matched non-attendees (HR 1.58, 95\% 1.53 to 1.63 ) and antihypertensives (HR 1.06, 95\% 1.03 to 1.10 ).${ }^{17} \mathrm{HC}$ attendees have also been shown to have reduced CVD risk scores, BP and serum lipids a year afterwards. ${ }^{18}$ However, a significant limitation of existing studies is that they have used observational data comparing $\mathrm{HC}$ attendees and non-attendees. Only a proportion of those invited for an HC actually attend, and those attending are not representative of the eligible population. ${ }^{16}{ }^{17}$ This study aims to evaluate the effect of invitation for an $\mathrm{HC}$ (ie, not just attendance) in terms of uptake and risk factor detection and management in eligible participants.

\section{METHODS}

\section{Study population and data source}

This study took place in Hampshire, a region in the south of England comprising over 1.5 million residents in a mixture of urban, suburban and rural settings. In Hampshire, the HC is commissioned by three local authorities: Southampton City Council, Portsmouth City Council and Hampshire County Council. The two largest urban areas in Hampshire are the cities of Southampton and Portsmouth, each with a population of around 200 000-250 000 . There were 151 GPs that contributed data to this study, around $80 \%$ of the total in the region. The organisation of the HC programme in Hampshire involved assigning eligible patients into five separate cohorts. Cohort assignment was based on date of birth (DOB), although the cohorts had comparable means and distributions of ages. This method of assignment (ie, based on birth year) constituted a form of 'quasi-randomisation'. ${ }^{19}$ Specifically, patients with years of birth ending in ' 0 ' or ' 5 ' were assigned to one cohort, ' 1 ' or ' 6 ' to another cohort, '2' or ' 7 ' to another and so forth, mirroring the quinquennial invitation system used for NHS breast cancer screening. The first cohort (cohort 1) was invited for an HC in the year 1 April 2011-31 March 2012, while the subsequent cohorts (cohorts 2-5) were invited in the years beginning 1 April 2012 to 2015. The study period was from 1 April 2011 to 31 March 2015. During this time, cohorts 1-4 were invited for HCs. Cohort 5 was eligible for an HC but not invited (ie, until after the follow-up period ended) and was our control group. We compared outcomes in each of the invited cohorts 1-4 separately against those in cohort 5. The exact follow-up periods depended on the cohorts being compared and are described below.

The population for this study were eligible for an $\mathrm{HC}$ on 1 April 2011. This required a DOB between 1 April 1940 and 31 March 1976 and (as of 1 April 2011) (1) no history of vascular disease (eg, coronary artery disease, cerebrovascular disease, atherosclerosis, peripheral vascular disease or circulatory system disease); (2) no previous diagnosis of hypertension, diabetes, CKD, atrial fibrillation (AF), heart failure, stroke or transient ischaemic attack; and (3) no pre-existing records of receiving statin prescription, palliative care, a health check or CVD risk assessment. These medical eligibility criteria matched the criteria used locally by GPs to identify and invite participants to participate in the HC programme. The Read Codes for eligibility and outcomes are included as online supplementary 


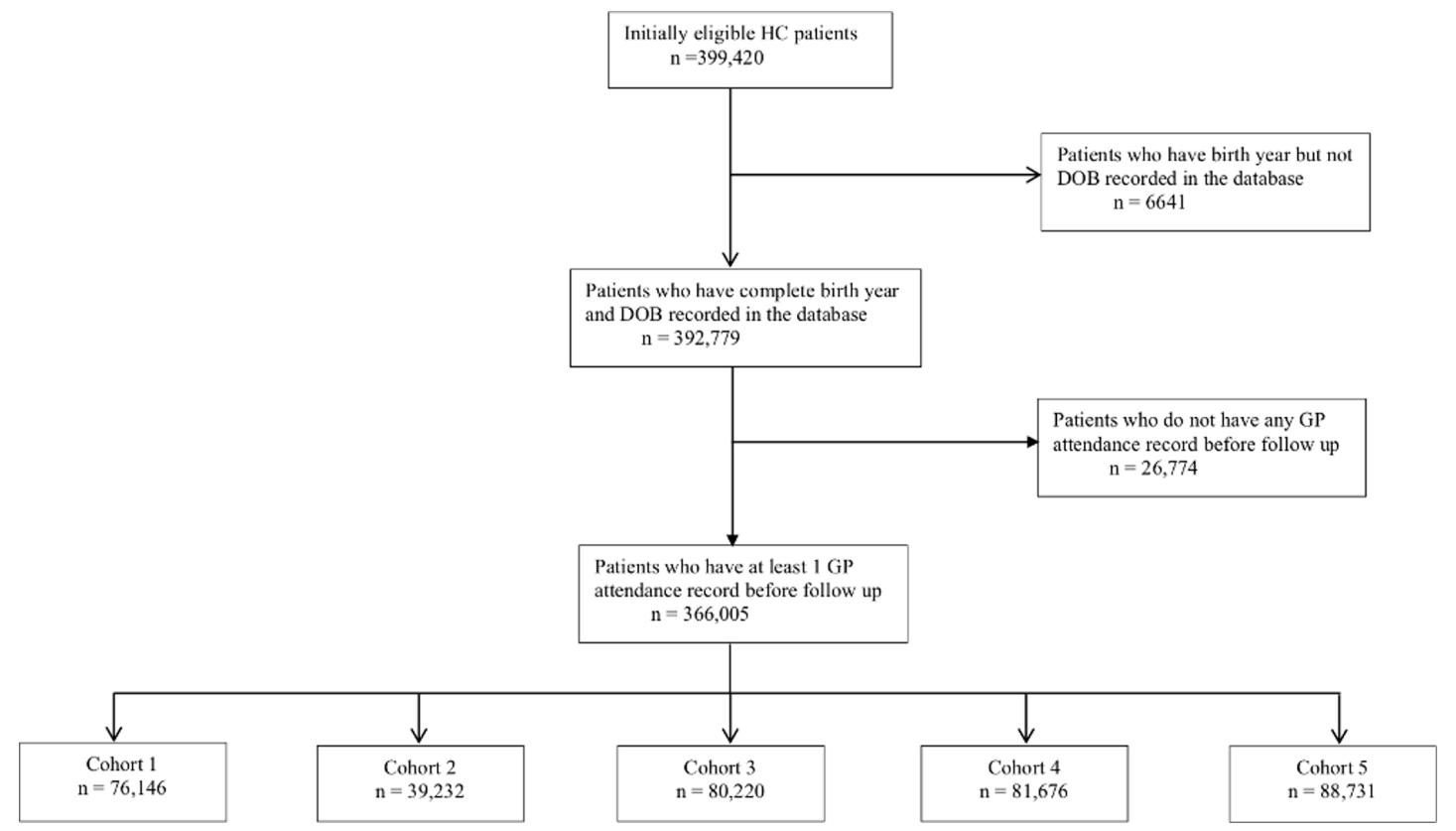

Figure 1 Derivation of the study population and five cohorts included in this study. Cohorts 1-4 were invited for HC in the years beginning 1 April 2011, 2012, 2013 and 2014, respectively, while cohort 5, which was the control group, was not invited. DOB, date of birth; GP, general practice; HC, Health Checks.

information. Using participants' DOBs, we assigned them into cohorts $1-5$ to identify the years they were invited for an HC between 1 April 2011 and 31 March 2015 (or not invited in the case of cohort 5). As is explained below, for some analyses, we reapplied the eligibility criteria to identify participants still eligible for an HC at the start of each invitation year.

As there was a temporary pause in sending out $\mathrm{HC}$ invitations during the first half of the year beginning 1 April 2012 in the Hampshire County Council Local Authority, we excluded patients belonging to cohort 2 living in that area ( 40000 participants). We excluded patients with no recorded DOB (6641) or no GP attendance record before 1 April 2011 (26 774), as we assumed that those patients had moved into the area after the start of the follow-up. We excluded patients with medical records not formatted according to Read Codes V.2 ( 70 000). In total, we excluded around 35\% of the population.

We acquired data for this study from the Hampshire Health Record Analytical Database (HHRA). At the time of the study, the HHRA linked anonymised clinical records from 151 primary care practices, secondary care (eg, inpatient, outpatient, and accident and emergency) from three acute (hospital) NHS trusts, and laboratory and pathology tests. The HHRA also contained deprivation indices for the populations served by the included GPs. The HHRA covers a registered population of around 1.5 million patients. Unfortunately, the organisation or the HHRA is such that some patients who die are removed from the database. As such, we did not use mortality or CVD events, which frequently result in death, as outcomes.

\section{Information extracted and outcome measures}

For each participant, we extracted from HHRA data concerning HC attendance, age, gender and individual level deprivation (Index of Multiple Deprivation (IMD)) at baseline. Ethnicity was poorly recorded (50\% missing) and, in any case, this information was not released for analysis due to concerns about identifiability. We extracted data for the following outcomes: (1) recording of BP, total serum cholesterol (TC), smoking status (ie, 'current smoker', 'ex-smoker' and 'never smoker'), BMI and 10-year CVD risk score (eg, Framingham and QRISK); (2) detection of CVD risk score $>10 \%$, CVD risk score $>20 \%$, current smoker, TC $>5.5 \mathrm{mmol} / \mathrm{L}, \mathrm{TC}>7.5 \mathrm{mmol} / \mathrm{L}$ and $\mathrm{BMI}>30 \mathrm{~kg} / \mathrm{m}^{2}$; (3) new diagnoses of hypertension, $\mathrm{AF}$, diabetes and CKD (stage $\geq 3$ ); and (4) new interventions with statins, antihypertensives, antiglycaemic medication, nicotine replacement therapy (NRT), antiobesity medication, stop smoking advice/referral and weight management advice/referral. We identified outcomes only where corresponding Read Codes had been recorded (eg, we did not assume that BMI had been measured just because a weight management referral had been made). Data were extracted from the HHRA in January 2017.

\section{Follow-up periods and statistical analysis}

For each cohort overall and for HC attendees/non-attendees within each cohort separately, we calculated baseline means and SD of age, gender and IMD. We calculated proportions (\%) with outcomes occurring between 1 April 2011 and 31 March 2015. We calculated absolute differences in these proportions for each of cohorts 1-4 vs cohort 5 (ie, invited vs non-invited) as well as the range (ie, of absolute differences for cohorts 1-4 vs cohort 5). 
We also compared proportions with outcomes among attendees and non-attendees. $\chi^{2}$ test was used to test for equality between proportions.

In the second stage of our analysis, we calculated ORs for each outcome. We employed multivariable logistic regression models adjusted for age and gender. We calculated ORs for each invited cohort (ie, cohorts 1-4) separately, with the reference being uninvited cohort 5 . The rationale for this approach was to capture changes in performance over a time period when awareness and experience among patients and providers were increasing. Evaluation of earlier years (eg, cohort 1) is still of interest because of longer follow-up, but the most recently invited cohort (ie, cohort 4) may be most reflective of current practice. Finally, to examine whether the impact of the programme differed by deprivation, we reran the regression analysis for the most recently invited cohort (ie, cohort 4) versus uninvited cohort 5 while including an interaction term for IMD.

All analyses were by intention-to-treat. We did sensitivity analysis by excluding those who attended opportunistically. In these analyses, follow-up was from the start of the invitation year of the invited cohort until 31 March 2015. Specifically, for cohorts 1-4 vs cohort 5, follow-up periods were from 1 April 2011, 1 April 2012, 1 April 2013, 1 April 2014, respectively, until 31 March 2015. We included only participants still eligible at the start of the invitation year. As invitations were sent out throughout each year rather than all at the start, participants were invited on average 6 months from the start of their invitation years. This corresponds to follow-up periods for comparisons of cohorts 1-4 vs cohort 5 , respectively, of 3.5, 2.5, 1.5 and 0.5 years. Data extraction was implemented using SQL Server 2008 R2, and statistical analyses were conducted using R (V.3.5.1, R Foundation for Statistical Computing, Vienna, Austria) ${ }^{20}$

\section{Patient and public involvement}

There were no patients directly involved in the planning or design of this study.

\section{RESULTS}

\section{Study sample and baseline characteristics}

The derivation of the study population and five cohorts is shown in figure 1 . There were 399420 patients who met our inclusion criteria and who had medical records formatted as Read Codes V.2. From those, we excluded 6641 without a recorded DOB and a further 26774 patients without entries in their health records from before 1 April 2011 who likely moved into Hampshire after the start of the follow-up period. The remaining 366005 participants formed our study population. Table 1 summarises their baseline characteristics broken down into cohorts $1-5$. The cohorts had similar proportions of male gender (within 1\%) and mean deprivation scores (within one centile). The cohorts differed more markedly in mean age, although the maximum difference was

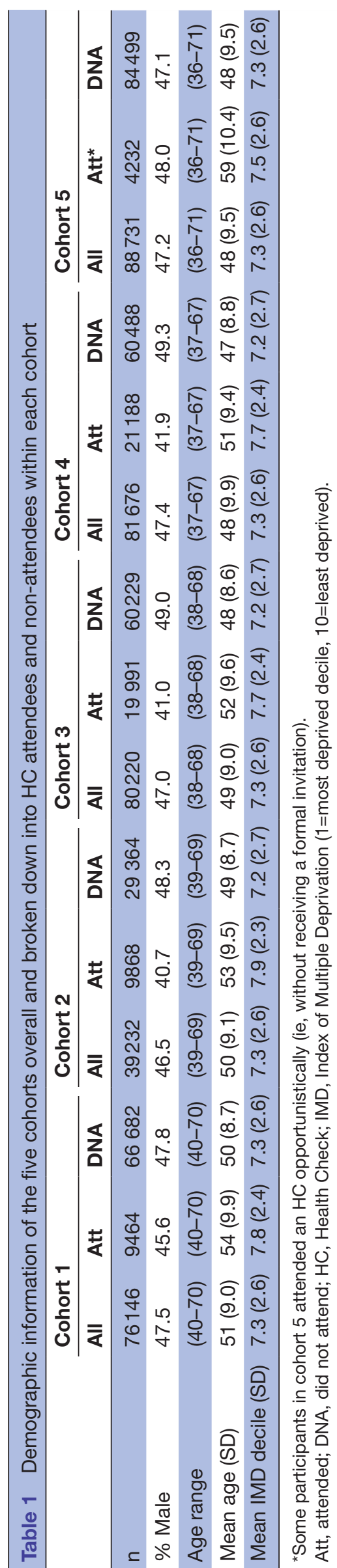



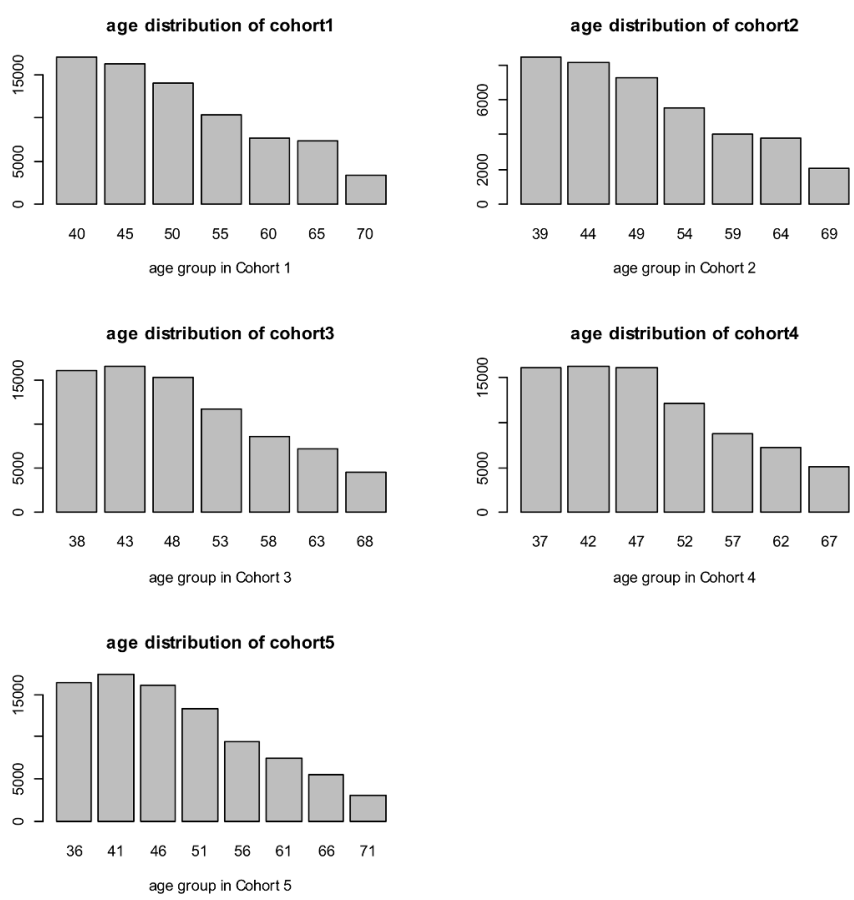

Figure 2 Histograms showing the distribution of ages within the five cohorts.

just 3 years between cohorts 1 and 5 . The age differences reflected the HC invitation system in Hampshire which, as is described above, is based on DOB. However, figure 2 shows histograms with broadly similar distributions of ages within each cohort.

HC attendees in all cohorts were more likely to be female, older and less deprived compared with those who did not attend (table 1). Proportions within each invited cohort (ie, cohorts 1-4) attending HCs increased year on year during the follow-up, and for cohorts 1-4 were $12 \%, 27 \%, 28 \%$ and $30 \%$, respectively. Despite not being formally invited, a number of patients in cohort 5 attended an HC during the follow-up period. These patients had likely responded to local or national advertising for the HC programme or had been offered HCs opportunistically by their GPs.

\section{Proportions of risk factor recording, detection, diagnoses and interventions}

Table 2 summarises the proportions of patients with recording and detection of risk factors, new diagnoses and new interventions during the follow-up period, which varied by cohort. The results are shown for each cohort overall and separately for attendees and non-attendees within each cohort. Given the large sample size, even small differences in proportions between cohorts were frequently highly significant (see online supplementary information for $\mathrm{p}$ values). Proportions generally increased year on year for cohorts 1-4, reflecting increasing attendance, and were lowest in the uninvited cohort 5. There were significant $(\mathrm{p}<0.001)$ increases in absolute proportions in invited cohorts $1-4$ with recorded BP (range for cohorts $1-4$ vs cohort $5=4.9 \%-7.9 \%)$, BMI $(5.0 \%-13.4 \%)$,
TC $(8.4 \%-17.4 \%)$, CVD risk $(7.4 \%-19.6 \%)$ and smoking status $(2.8 \%-7.0 \%)$. There were also significant increases in detection of CVD risk $>10 \%(2.0 \%-3.6 \%), \mathrm{SBP}>140 /$ $\mathrm{DBP}>90(1.0 \%-2.1 \%), \mathrm{BMI}>30 \mathrm{~kg} / \mathrm{m}^{2}(0.9 \%-2.5 \%)$, TC $>5.5 \mathrm{mmol} / \mathrm{L}(4.1 \%-7.0 \%)$ and TC $>7.5 \mathrm{mmol} / \mathrm{L}(0.3 \%-$ $0.4 \%)$. There were more modest or not consistently significant differences in proportions with detected CVD risk $>20 \%(0.1 \%-0.6 \%)$ and current smoking $(-0.3 \%$ to $0.5 \%)$.

The proportions with detection of risk factors among those with recordings were lower in the invited cohorts (ie, cohorts 1-4) compared with uninvited cohort 5, particularly for CVD risk $>10 \%(-11.5 \%$ to $-2.9 \%),>20 \%$ $(-6.1 \%$ to $-1.8 \%)$ and $\mathrm{BMI}>30 \mathrm{~kg} / \mathrm{m}^{2}(-2.8 \%$ to $-1.0 \%)$. Even though smaller absolute numbers of high-risk patients were identified by opportunistic testing, these data suggest a higher positive predictive value of opportunistic testing compared with the $\mathrm{HC}$, which may reflect the different risk profiles of patients.

$\mathrm{HC}$ resulted in minor or no increases in proportions with new diagnoses of hypertension $(0.3 \%-0.6 \%)$, AF $(0.0 \%-0.1 \%)$, CKD $(0.0 \%-0.1 \%)$ or diabetes $(0.0 \%-$ $0.1 \%)$. There were minor increases in proportions receiving statins $(0.2 \%-0.9 \%)$, antihypertensives $(0.2 \%-$ $0.6 \%)$ and stop smoking advice $(0.4 \%-0.9 \%)$, but no consistent difference in antiglycaemics $(-0.1 \%$ to $0.0 \%)$, NRT $(0.0 \%)$ or antiobesity medications $(0.0 \%)$. There was an increase in weight advice/referrals $(4.6 \%-10.5 \%)$.

Proportions receiving statins were lower among $\mathrm{HC}$ invited cohorts compared with non-invited following detection of CVD risk $>10 \%(-7.4 \%$ to $-1.1 \%)$ and $>20 \%$ $(-5.5 \%$ to $-1.2 \%)$. Similarly, antiglycaemic interventions among new cases of diabetes were lower $(-3.5 \%$ to $-1.8 \%)$, as were new antiobesity prescriptions following detection of $\mathrm{BMI}>30 \mathrm{~kg} / \mathrm{m}^{2}(-0.3 \%$ to $-0.1 \%)$. Differences in proportions receiving antihypertensives following new hypertension diagnoses were inconsistent $(-0.6 \%$ to $0.2 \%)$, but there was an increase in proportions among $\mathrm{HC}$ invitees receiving weight advice/referral following detection of $\mathrm{BMI}>30 \mathrm{~kg} / \mathrm{m}^{2}(6.0 \%-13.6 \%)$.

\section{ORs of risk factor detection, diagnoses and interventions}

Table 3 summarises the ORs and 95\% CIs from the regression analyses. Compared with uninvited cohort 5 (including and excluding those who attended opportunistically), the odds of detection of risk factors, new diagnoses and interventions were generally higher in invited cohorts 1-4, and they increased year on year throughout the study period. For cohort 4 vs cohort 5 , there were large and significant increases in the odds of detecting CVD risk $>10 \%$ (OR 8.01, 95\% CI 7.34 to 8.73), CVD risk $>20 \%$ (OR 5.86, 95\% CI 4.83 to 7.10 ), TC $>5.5 \mathrm{mmol} / \mathrm{L}$ (OR 3.72, 95\% CI 3.57 to 3.89 ), TC $>7.5 \mathrm{mmol} / \mathrm{L}$ (OR 2.89, $95 \%$ CI 2.46 to 3.38 ) and BMI $>30 \mathrm{~kg} / \mathrm{m}^{2}$ (OR 2.05, $95 \%$ CI 1.96 to 2.14 ). These may be conservative given that the average follow-up was just 6 months, and for some participants almost none, while many outcomes from the HC would likely take longer to occur. There 
Table 2 Proportions of participants with risk factor recording/detection, new diagnoses and new interventions in each of the five cohorts overall and for $\mathrm{HC}$ attendees and non-attendees within each cohort separately

\section{Cohort 1 \\ Cohort 2 \\ Cohort 3 \\ Cohort 4 \\ Cohort 5 \\ All Att DNA All Att DNA All Att DNA All Att DNA All Att DNA}

Recording (\%)

$\mathrm{BP}$

$\begin{array}{lllllllllllllll}72.3 & 98.6 & 68.5 & 75.2 & 98.6 & 67.3 & 74.3 & 98.7 & 66.3 & 73.3 & 98.6 & 64.4 & 67.3 & 99.1 & 65.7\end{array}$

$\begin{array}{llllllllllllllll}\text { BMI } & 48.4 & 97.7 & 41.4 & 56.5 & 98.5 & 42.3 & 56.5 & 98.5 & 42.5 & 56.8 & 98.6 & 42.2 & 43.4 & 98.0 & 40.6\end{array}$

TC

$\begin{array}{lllllllllllllll}41.5 & 97.6 & 33.6 & 49.5 & 97.1 & 33.6 & 49.4 & 97.0 & 33.6 & 50.6 & 97.2 & 34.2 & 33.1 & 96.1 & 30.0\end{array}$

CVD risk

$\begin{array}{lllllllllllllll}23.0 & 89.0 & 13.7 & 32.8 & 89.4 & 13.8 & 33.2 & 89.1 & 14.7 & 35.3 & 92.3 & 15.3 & 15.7 & 90.2 & 11.9\end{array}$

Smoking status

$\begin{array}{lllllllllllllll}71.8 & 98.5 & 68.1 & 75.8 & 98.9 & 68.0 & 75.7 & 98.7 & 68.1 & 76.0 & 98.4 & 68.2 & 69.0 & 98.7 & 67.6\end{array}$

Detection (\%)

CVD risk $>10 \%$

$\begin{array}{lllllllllllllll}7.7 & 29.0 & 4.7 & 9.3 & 23.0 & 4.7 & 9.0 & 22.2 & 4.6 & 8.8 & 20.7 & 4.6 & 5.7 & 44.5 & 3.8\end{array}$

$\begin{array}{llllllllllllllll}\text { \% of CVD risk recorded } & 33.6 & 32.6 & 34.5 & 28.4 & 25.7 & 34.3 & 27.0 & 24.9 & 31.1 & 24.9 & 22.5 & 30.1 & 36.4 & 49.3 & 31.5\end{array}$ with $>10 \%$

\begin{tabular}{|c|c|c|c|c|c|c|c|c|c|c|c|c|c|c|c|}
\hline CVD risk $>20 \%$ & 2.2 & 8.1 & 1.3 & 2.4 & 5.2 & 1.4 & 2.1 & 4.4 & 1.3 & 1.8 & 3.6 & 1.2 & 1.8 & 15.0 & 1.1 \\
\hline $\begin{array}{l}\% \text { of CVD risk recorded } \\
\text { with }>20 \%\end{array}$ & 9.4 & 9.1 & 9.6 & 7.2 & 5.8 & 10.1 & 6.3 & 5.0 & 9.1 & 5.1 & 3.9 & 7.8 & 11.2 & 16.6 & 9.1 \\
\hline $\begin{array}{l}\text { SBP }>140 \text { or DBP } \\
>90 \mathrm{~mm} \mathrm{Hg}\end{array}$ & 17.8 & 24.6 & 16.8 & 17.5 & 20.1 & 16.6 & 17.3 & 20.6 & 16.3 & 16.6 & 19.7 & 15.6 & 15.7 & 29.9 & 14.9 \\
\hline $\begin{array}{l}\% \text { of BP recorded with } \\
>140 \text { or }>90\end{array}$ & 24.6 & 25.0 & 24.5 & 23.3 & 20.4 & 24.7 & 23.3 & 20.8 & 24.5 & 22.7 & 20.0 & 24.2 & 23.3 & 30.2 & 22.7 \\
\hline Current smoker & 20.7 & 17.0 & 21.2 & 20.8 & 14.6 & 22.8 & 20.9 & 14.4 & 23.1 & 21.4 & 16.3 & 23.2 & 20.9 & 18.4 & 21.1 \\
\hline $\begin{array}{l}\% \text { of smoking status } \\
\text { recorded who currently } \\
\text { smoke }\end{array}$ & 28.8 & 17.3 & 31.1 & 27.4 & 14.8 & 33.6 & 27.6 & 14.6 & 33.9 & 28.2 & 16.6 & 34.1 & 30.3 & 18.6 & 31.2 \\
\hline $\mathrm{BMI}>30 \mathrm{~kg} / \mathrm{m}^{2}$ & 12.6 & 18.0 & 11.9 & 13.9 & 17.6 & 12.7 & 13.8 & 17.9 & 12.4 & 14.3 & 19.7 & 12.3 & 11.8 & 20.1 & 11.4 \\
\hline $\begin{array}{l}\% \text { BMI recorded with } \\
>30\end{array}$ & 26.1 & 18.5 & 28.7 & 24.7 & 17.9 & 30.0 & 24.4 & 18.2 & 29.1 & 25.1 & 20.0 & 29.2 & 27.2 & 20.5 & 28.0 \\
\hline $\mathrm{TC}>5.5 \mathrm{mmol} / \mathrm{L}$ & 19.1 & 44.1 & 15.5 & 22.0 & 43.1 & 14.9 & 21.4 & 41.4 & 14.8 & 21.6 & 39.8 & 15.2 & 15.0 & 48.8 & 13.3 \\
\hline $\begin{array}{l}\% \text { of TC recorded with } \\
>5.5 \mathrm{mmol} / \mathrm{L}\end{array}$ & 46.0 & 45.2 & 46.2 & 44.3 & 44.4 & 44.3 & 43.3 & 42.7 & 43.9 & 42.7 & 40.9 & 44.4 & 45.3 & 50.8 & 44.4 \\
\hline $\mathrm{TC}>7.5 \mathrm{mmol} / \mathrm{L}$ & 1.4 & 2.7 & 1.2 & 1.5 & 2.4 & 1.2 & 1.5 & 2.5 & 1.1 & 1.5 & 2.3 & 1.3 & 1.1 & 3.3 & 1.0 \\
\hline $\begin{array}{l}\% \text { of TC recorded with } \\
>7.5 \mathrm{mmol} / \mathrm{L}\end{array}$ & 3.3 & 2.8 & 3.6 & 3.1 & 2.5 & 3.6 & 3.0 & 2.6 & 3.3 & 3.1 & 2.4 & 3.8 & 3.4 & 3.4 & 3.4 \\
\hline
\end{tabular}

Diagnoses (\%)

$\begin{array}{llllllllllllllll}\text { Hypertension } & 4.2 & 4.7 & 4.1 & 4.1 & 3.7 & 4.3 & 3.9 & 3.0 & 4.2 & 4.0 & 2.5 & 4.5 & 3.6 & 6.5 & 3.5\end{array}$

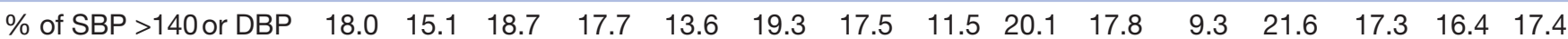

$>90$ with hypertension

diagnosis

\begin{tabular}{lrrrrrrrrrrrrrrr} 
AF & 0.5 & 0.5 & 0.5 & 0.4 & 0.4 & 0.4 & 0.4 & 0.4 & 0.5 & 0.4 & 0.2 & 0.4 & 0.4 & 0.9 & 0.3 \\
\hline CKD & 0.3 & 0.3 & 0.3 & 0.3 & 0.4 & 0.3 & 0.3 & 0.2 & 0.3 & 0.3 & 0.1 & 0.3 & 0.2 & 0.6 & 0.2 \\
\hline $\begin{array}{l}\text { Diabetes } \\
\begin{array}{l}\text { Interventions (\%) } \\
\text { Statin }\end{array}\end{array}$ & 1.3 & 0.9 & 1.3 & 1.2 & 0.7 & 1.4 & 1.3 & 0.6 & 1.5 & 1.3 & 0.6 & 1.6 & 1.2 & 1.2 & 1.2 \\
$\begin{array}{l}\text { \% of CVD >10\% } \\
\text { prescribed statins }\end{array}$ & 4.9 & 7.7 & 4.5 & 5.0 & 5.6 & 4.8 & 4.4 & 4.5 & 4.4 & 4.3 & 3.3 & 4.6 & 4.0 & 13.0 & 3.6 \\
$\begin{array}{l}\text { \% of CVD > 20\% } \\
\text { prescribed statins }\end{array}$ & 40.7 & 16.5 & 27.8 & 18.8 & 12.7 & 28.8 & 17.6 & 11.4 & 27.5 & 16.2 & 9.3 & 27.0 & 23.6 & 19.0 & 26.2 \\
Antihypertensives & 7.5 & 48.8 & 37.9 & 28.7 & 49.4 & 38.2 & 27.4 & 50.2 & 36.5 & 23.0 & 50.8 & 41.9 & 33.9 & 47.5 \\
\hline
\end{tabular}

Continued 
Table 2 Continued

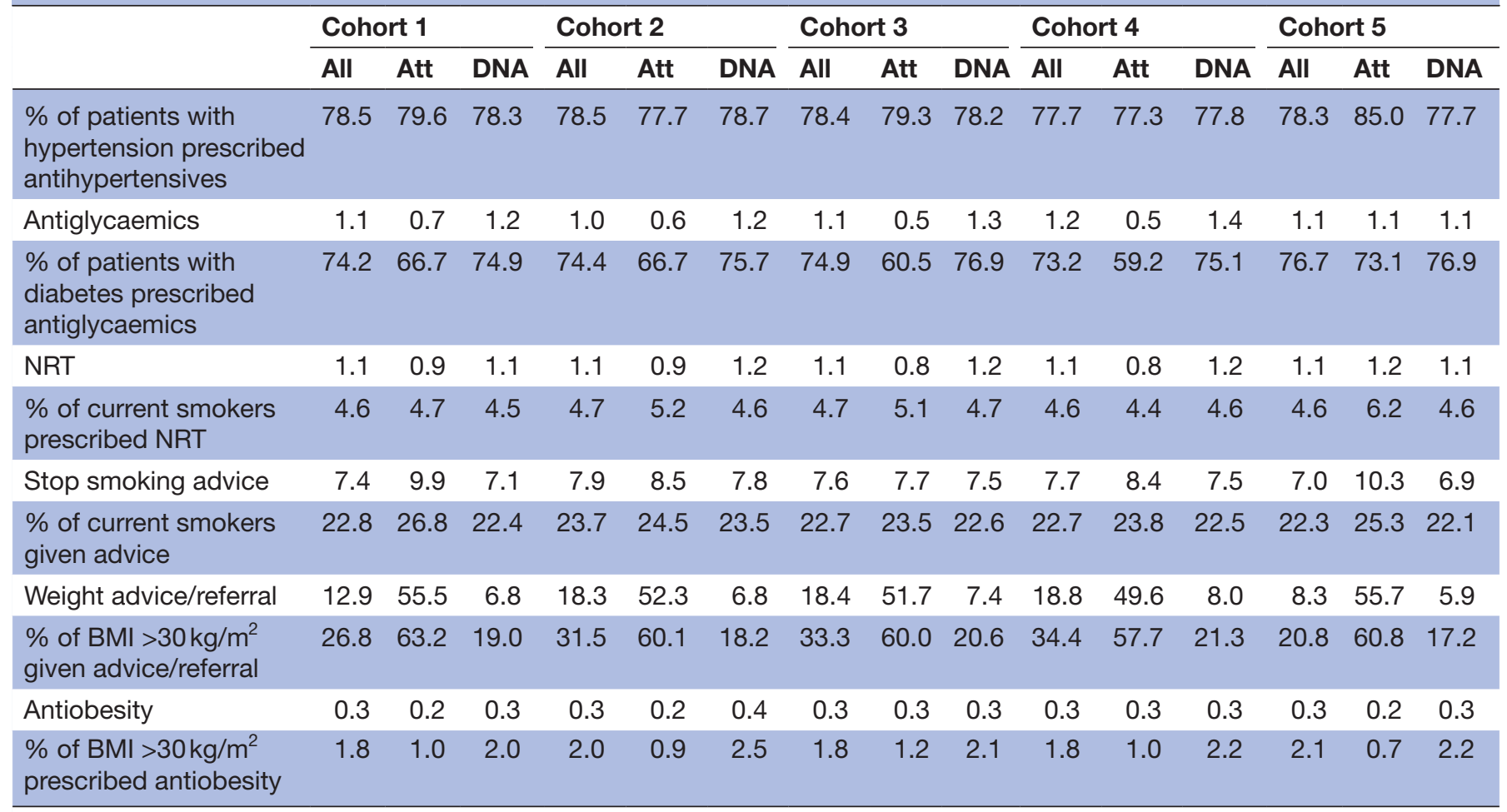

AF, atrial fibrillation; Att, attended; BMI, body mass index; BP, blood pressure; CKD, chronic kidney disease; CVD, cardiovascular disease; DBP, diastolic blood pressure; DNA, did not attend; HC, Health Check; NRT, nicotine replacement therapy; SBP, systolic blood pressure; TC, total cholesterol.

were significant increases in detection of current smokers (OR 1.22, 95\% CI 1.18 to 1.26$)$ and elevated BP (OR 1.64, $95 \%$ CI 1.57 to 1.70$)$. There were modest increases in new diagnoses of hypertension (OR $1.33,95 \%$ CI 1.20 to 1.47 ) and diabetes (OR 1.34, $95 \%$ CI 1.12 to 1.61 ), but not $\mathrm{AF}$ (OR $1.00,95 \%$ CI 0.72 to 1.39 ) or CKD (OR $0.69,95 \%$ CI 0.36 to 1.32$)$. In terms of new interventions, there were increases in weight advice/referrals (OR 8.36, 95\% CI 7.89 to 8.86 ), stop smoking advice (OR $1.65,95 \%$ CI 1.51 to 1.79 ), statins (OR $1.54,95 \%$ CI 1.39 to 1.71 ) and antihypertensives (OR 1.15, 95\% CI 1.06 to 1.24 ). The ORs of CVD risk $>10 \%$ plus statin or $>20 \%$ plus statin, respectively, were 2.90 (95\% CI 2.36 to 3.57 ) and 2.60 (95\% CI 1.92 to 3.52$)$. The OR of hypertension diagnosis plus antihypertensive treatment was 1.33 (95\% CI 1.18 to 1.50 ). There were no significant differences in prescriptions of NRT (OR $0.92,95 \%$ CI 0.71 to 1.20 ), antiglycaemics (OR $1.18,95 \%$ CI 0.97 to 1.44 ) or antiobesity medications (OR $1.00,95 \%$ CI 0.68 to 1.48$)$.

Table 4 shows the demographics of participants in cohort 4 who were eligible at the beginning of their invitation year stratified according to national IMD quintile. There was a disproportionately high number of participants in the least deprived quintile, which reflected the affluence of the study area compared with the national average. The proportion attending an $\mathrm{HC}$ was also highest in this quintile. Table 5 shows the ORs for outcomes in invited cohort 4 , with reference to uninvited cohort 5 , stratified according to national IMD quintile. The effects of IMD were significant (at the $\mathrm{p}=0.05$ level) between IMD and detection of 10-year CVD risk $>10 \%$, SBP $>140$ or DBP $>90 \mathrm{~mm} \mathrm{Hg}$, BMI $>30 \mathrm{~kg} / \mathrm{m}^{2}, \mathrm{TC}>5.5 \mathrm{mmol} / \mathrm{L}$ and TC $>7.5 \mathrm{mmol} / \mathrm{L}$, as well as weight advice/referral.

\section{DISCUSSION}

This study evaluated the NHS HC programme in Hampshire from its implementation in April 2011 until March 2015. HC attendance following invitation increased year on year and as of 2015 was $30 \%$. Attendees were older, from less deprived backgrounds and less likely to be male than those who were invited but chose not to attend. A significant finding was the large increase of up to $17.5 \%$ in the proportion of patients with measurements of TC among HC invited cohorts compared with non-invited. As might be expected, this led to large increases in detection of elevated TC $>5.5 \mathrm{mmol} / \mathrm{L}$ and CVD risk $>10 \%$, as well as TC $>7.5 \mathrm{mmol} / \mathrm{L}$ and CVD risk $>20 \%$. Notwithstanding, there were only modest increases in detection plus treatment with statins. Explanations for this might include guidance during the study period recommending statins for CVD risk $>20 \%$, whereas the largest increase was in detection of CVD risk $>10 \%$. Nonetheless, even among those with CVD risk $>20 \%$, only $36.5 \%-40.7 \%$ (range for the invited cohorts) of participants were prescribed statins. This is substantially lower than the $85 \%$ used in 


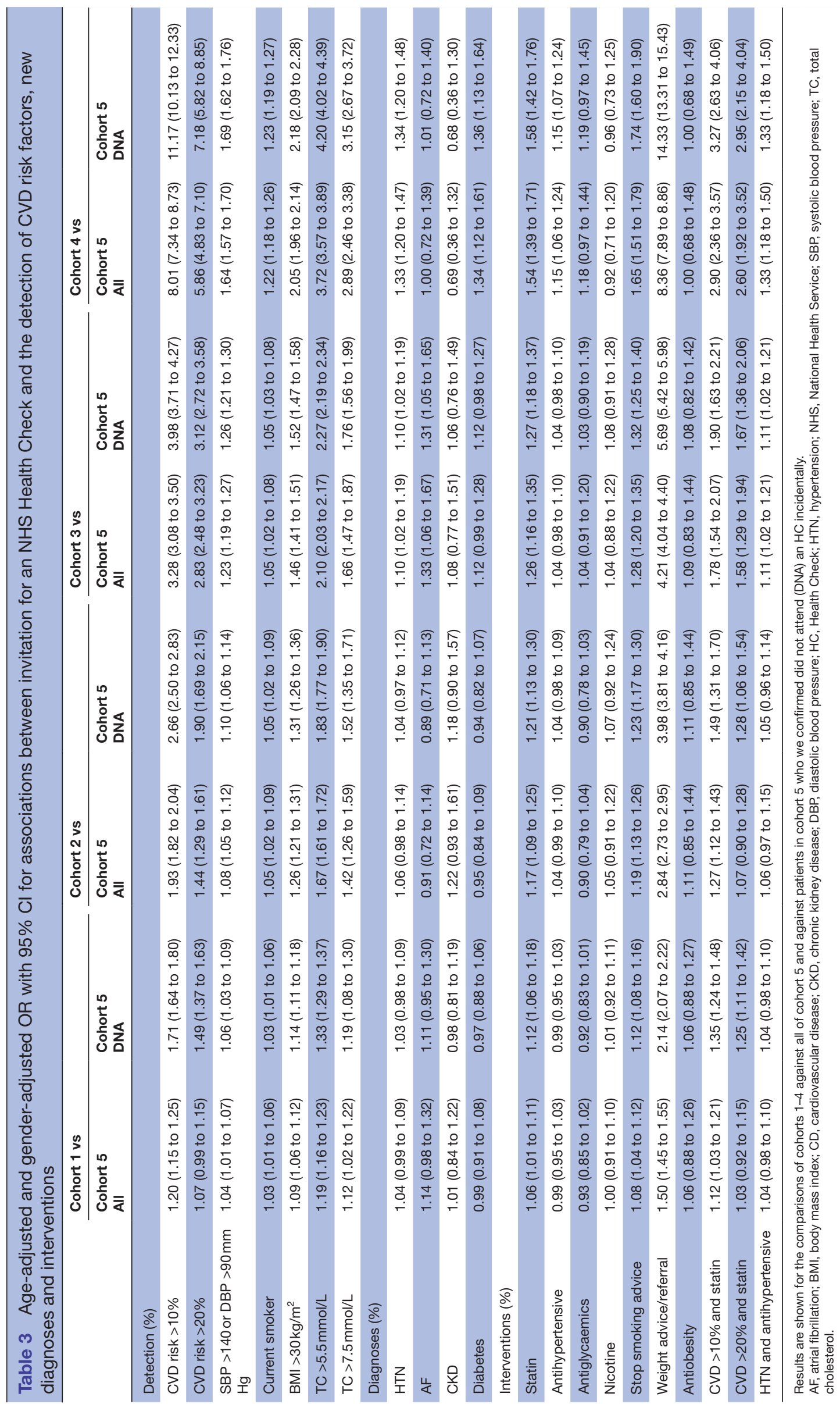


Table 4 Number of participants and proportion of men and $\mathrm{HC}$ attendees in cohort 4 according to national IMD quintile, where quintile 5 is the least deprived

\begin{tabular}{lrrrrr}
\hline & Q1 & Q2 & Q3 & Q4 & \multicolumn{1}{l}{ Q5 } \\
\hline $\mathrm{n}$ & 3775 & 9083 & 10792 & 15098 & 30238 \\
\% Male & 50.8 & 49.5 & 47.5 & 46.4 & 45.8 \\
\% Attended & 24.1 & 26.7 & 32.9 & 37.2 & 40.7 \\
HC & & & & & \\
\hline
\end{tabular}

HC, Health Check; $Q$, quintile (1=most deprived, $5=$ =east deprived).

modelling studies by the Department of Health. ${ }^{5}$ In the uninvited group, rates of statin prescriptions following identification of CVD risk $>20 \%$ were slightly higher $(41.9 \%)$, but still lower than expected. Accordingly, there may be a more general issue relating to the step-up from risk factor identification to diagnosis, and from diagnosis to treatment across GPs that would represent a missed opportunity at a population level for primary prevention of CVD. More specifically to the HC, there is a lack of a defined follow-up pathway following identification of increased 10-year CVD risk. Public Health England commissions and pays for the HC itself, but follow-up is then a cost to GPs, which may be a barrier.

Statin prescription rates may have increased since the study period, as updated National Institute for Health and Care Excellence (NICE) guidance now recommends statins for CVD risk $>10 \%$ and a recent large and well-publicised review reported a more favourable risk/ benefit profile of statins than thought previously. ${ }^{21}$ Statin prescription rates resulting from an HC may also be higher outside of Hampshire, as they are known to vary locally. ${ }^{22}$

Other notable findings of this study included increased detection of elevated BP among HC invited cohorts, as well as modest increases in new diagnoses of hypertension and treatment. Those attending HCs were more

Table 5 Age-adjusted and gender-adjusted OR with $95 \% \mathrm{Cl}$ for associations between invitation for an NHS Health Check and the detection of CVD risk factors, new diagnoses and interventions

\begin{tabular}{|c|c|c|c|c|c|}
\hline Detection & Q1 & Q2 & Q3 & Q4 & Q5 \\
\hline CVD risk $>10 \%$ & 3.02 (2.14 to 4.28$)$ & 6.15 (4.78 to 7.90$)$ & 7.82 (6.21 to 9.84$)$ & 7.99 (6.67 to 9.58$)$ & 9.67 (8.49 to 11.03$)$ \\
\hline CVD risk $>20 \%$ & 3.99 (1.88 to 8.48$)$ & 5.30 (3.11 to 9.01$)$ & 6.96 (4.05 to 11.96$)$ & 7.21 (4.63 to 11.21$)$ & 5.56 (4.22 to 7.33$)$ \\
\hline Current smoker & 1.17 (1.06 to 1.30$)$ & 1.16 (1.08 to 1.25$)$ & 1.25 (1.16 to 1.35$)$ & 1.25 (1.17 to 1.35$)$ & 1.25 (1.18 to 1.33 ) \\
\hline $\mathrm{TC}>7.5 \mathrm{mmol} / \mathrm{L}$ & $1.10(0.63$ to 1.93$)$ & 3.47 (2.10 to 5.75$)$ & 2.09 (1.44 to 3.03$)$ & 3.55 (2.44 to 5.16$)$ & 3.39 (2.66 to 4.34 ) \\
\hline \multicolumn{6}{|l|}{ Diagnoses } \\
\hline HTN & 1.65 (1.04 to 2.62 ) & 1.22 (0.92 to 1.61$)$ & 1.43 (1.12 to 1.82$)$ & 1.23 (0.99 to 1.54$)$ & 1.34 (1.14 to 1.57$)$ \\
\hline $\mathrm{AF}$ & 1.77 (0.29 to 10.65$)$ & 0.56 (0.19 to 1.64$)$ & 1.08 (0.50 to 2.30$)$ & 0.98 (0.50 to 1.92$)$ & 1.08 (0.65 to 1.79$)$ \\
\hline Statin & 1.46 (1.00 to 2.12 ) & 1.39 (1.06 to 1.82 ) & 1.37 (1.06 to 1.77 ) & 1.50 (1.19 to 1.89$)$ & 1.76 (1.48 to 2.09$)$ \\
\hline Antihypertensive & 1.20 (0.90 to 1.60$)$ & 1.17 (0.95 to 1.43$)$ & 1.19 (0.99 to 1.43$)$ & 1.14 (0.96 to 1.35$)$ & 1.13 (1.00 to 1.27$)$ \\
\hline Antiglycaemics & 1.15 (0.60 to 2.22$)$ & 1.05 (0.65 to 1.69$)$ & 1.04 (0.66 to 1.63$)$ & 1.04 (0.63 to 1.70$)$ & 1.44 (1.03 to 2.00$)$ \\
\hline Nicotine replace & 1.54 (0.75 to 3.17 ) & 0.54 (0.28 to 1.03$)$ & 1.14 (0.63 to 2.08$)$ & 0.63 (0.36 to 1.09$)$ & 1.31 (0.75 to 2.28$)$ \\
\hline Stop smoking advice & 1.84 (1.33 to 2.54$)$ & 1.46 (1.18 to 1.81$)$ & 1.48 (1.23 to 1.79$)$ & 1.62 (1.34 to 1.95$)$ & 1.82 (1.58 to 2.10$)$ \\
\hline Weight advice/referral & 4.48 (3.60 to 5.59$)$ & $6.42(5.47$ to 7.53$)$ & 7.68 (6.63 to 8.89$)$ & 8.17 (7.21 to 9.25$)$ & 10.21 (9.32 to 11.18$)$ \\
\hline Antiobesity & 0.82 (0.29 to 2.32) & $0.56(0.21$ to 1.48$)$ & 0.95 (0.44 to 2.05$)$ & 1.09 (0.45 to 2.62$)$ & 2.16 (0.87 to 5.36$)$ \\
\hline CVD risk $>10 \%$ and statin & $1.14(0.48$ to 2.70$)$ & 3.32 (1.94 to 5.66$)$ & 2.53 (1.52 to 4.20$)$ & 3.00 (1.90 to 4.71$)$ & 3.24 (2.34 to 4.49$)$ \\
\hline CVD risk $>20 \%$ and statin & $1.49(0.45$ to 4.96$)$ & 3.12 (1.52 to 6.41$)$ & 2.20 (1.00 to 4.85$)$ & 3.25 (1.55 to 6.81$)$ & 2.57 (1.63 to 4.05$)$ \\
\hline
\end{tabular}

Results are shown for invited cohort 4, with reference to uninvited cohort 5, stratified according to IMD quintile, where Q5 is the least deprived. The outcomes with a significant interaction $(\mathrm{p}<0.05)$ with IMD are shown in bold.

${ }^{*}$ Not applicable (insufficient data).

$\mathrm{AF}$, atrial fibrillation; BMI, body mass index; CKD, chronic kidney disease; CVD, cardiovascular disease; DBP, diastolic blood pressure; HTN, hypertension; IMD, Index of Multiple Deprivation; NHS, National Health Service; Q, quintile (1=most deprived, $5=$ least deprived); SBP, systolic blood pressure; TC, total cholesterol. 
likely to be diagnosed with diabetes, but the corresponding increase in prescriptions of antiglycaemics did not reach significance. According to HC guidance, diabetes screening is performed only in those deemed 'at risk' with BMI $\geq 30 \mathrm{~kg} / \mathrm{m}^{2}\left(\geq 25 \mathrm{~kg} / \mathrm{m}^{2}\right.$ in non-white ethnic groups) or SBP or DBP above $\geq 140 \mathrm{~mm} \mathrm{Hg}$ or $90 \mathrm{~mm} \mathrm{Hg}$. Data regarding the sensitivity of these criteria are limited, but one study in the USA reported that a BMI cut-off of $\geq 25 \mathrm{~kg} / \mathrm{m}^{2}$ 'would miss $36 \%$ of Asian Americans with newly diagnosed type 2 diabetes', ${ }^{23}$ so the HC may also have missed cases.

There was no significant increase in new diagnoses of CKD. This was likely because kidney function tests were performed only in HC patients with SBP or DBP $\geq 140 \mathrm{~mm}$ $\mathrm{Hg}$ or $90 \mathrm{~mm} \mathrm{Hg}$. A formal diagnosis of CKD would have required a repeat blood test, something which would need to have been organised by the GP and agreed to by the patient.

The HC did not result in any significant increase in new diagnoses of AF. NICE hypertension clinical guideline 127 states that practitioners should manually palpate the pulse before measuring $\mathrm{BP} .{ }^{24}$ However, this may not have been performed consistently or reliably during the HC. Manual palpation is not necessary with electronic sphygmomanometers, and any patient with an irregular pulse would have further required an ECG to diagnose AF.

There were increases in detection of smokers and BMI $>30 \mathrm{~kg} / \mathrm{m}^{2}$, as well as corresponding increases in lifestyle advice/referrals, particularly for high BMI. However, there was no significant difference in NRT or antiobesity medications.

The HC had lower positive predictive values (or yield) for detection of risk factors than checks performed opportunistically. Most notably, lower proportions of CVD risk scores measured during the HC were $>10 \%(-11.5 \%$ to $-2.9 \%)$ and $>20 \%(-6.1 \%$ to $-1.8 \%)$. This may have been because GPs targeted opportunistic checks at those who were already symptomatic or because $\mathrm{HC}$ attendees were healthier with a lower prevalence of risk factors. A recent cohort study of 18 GPs in South London also found that participants taking up an opportunistic $\mathrm{HC}$ were at higher CVD risk (17\% of invited HC and 22\% of opportunistic HC with CVD risk score $\geq 10 \%$ ), and that in younger adults in more deprived areas the opportunistic HC constituted a higher proportion of all HCs performed. It was concluded that GPs were successfully targeting groups at higher risk who may otherwise face barriers to attendance at a prearranged $\mathrm{HC}^{25}$

In the final year of this study, uptake of the $\mathrm{HC}$ was highest among participants in the least deprived national IMD quintile $(40.7 \%)$ and lowest in the most deprived $(24.1 \%)$. There was evidence of better performance of the $\mathrm{HC}$ among less deprived participants for detection of 10-year CVD risk $>10 \%, \mathrm{SBP}>140 \mathrm{~mm} \mathrm{Hg}$ or DBP $>90 \mathrm{~mm}$ $\mathrm{Hg}, \mathrm{BMI}, \mathrm{TC}>5.5 \mathrm{mmol} / \mathrm{L}$ and $\mathrm{TC}>7.5 \mathrm{mmol} / \mathrm{L}$, and weight advice/referral. However, the precise effect of deprivation was difficult to estimate given the competing effects of differences in HC uptake (lowest in the most deprived quintile), the frequency of risk variable (highest in the most deprived quintile) and differing sample sizes (ie, power to test/reject the null hypothesis). Primary care management may also have played a role, but the lack of difference by deprivation in prescribing rates in those detected suggests this was not a key factor.

Our findings build on existing evidence that attendees tend to be older, female and non-smokers. ${ }^{1626}$ The observation in this study that HC attendees were less likely to come from more deprived socioeconomic groups is reflected by some studies, ${ }^{27}$ although not by others. ${ }^{16}{ }^{26}$ Reasons for an inconsistent effect of deprivation are unclear, but may relate to local variation in targeting of high CVD risk individuals, who are over-represented in more deprived groups. An example of such targeting was reported by a study in East London, which found no effect of deprivation, where GPs were paid more for HCs that involved detection of higher CVD risk scores. ${ }^{22}$ In Hampshire, including the cities of Southampton and Portsmouth, there was no clear incentive to detect high CVD risk nor specific targeting of deprived communities.

Earlier studies report associations between HC attendance and increased recording and detection of CVD risk factors and use of interventions. ${ }^{17}$ It has also been shown that a year after completing an $\mathrm{HC}$, attendees have modest but significant reductions in CVD risk scores, DBP, TC levels and lipid ratios. ${ }^{18}$ However, Chang $e t a l^{26}$ found that only a third of $\mathrm{HC}$ attendees with CVD risk scores $>20 \%$ go on to be prescribed statins, slightly lower than that observed in the present study $(36.5 \%-40.7 \%)$. Reasons for low prescription rates among high-risk groups are unclear, but patient refusal might be important and requires further research. Similar to this study, Smith et $a l^{28}$ reported a limited effect of HC attendance on detection rates and treatment of diabetes, which as is explained above is likely because measuring blood glucose or HbAlc is not a standard part of the HC.

The increases in proportions of new prescriptions we observed were smaller than those found in two large previous matched studies. ${ }^{1726}$ This is to be expected given that those studies compared attendees versus non-attendees, whereas we considered invitees versus non-invitees. Given that not everybody invited for an HC will attend, our approach is more likely to be representative of the effect of the HC programme overall.

Strengths of this study included the biggest sample size to date for an HC study, comprising 277274 patients invited for an $\mathrm{HC}$ and 88731 patients who were not. It is the first HC study to employ a quasi-randomised method and an intention-to-treat analysis. Specifically, patients were allocated to either $\mathrm{HC}$ invited or non-invited group according to their DOBs. We were able to evaluate the $\mathrm{HC}$ programme at the level of invitation, which is advantageous compared with previous studies which compared attendance versus non-attendance. There were also weaknesses in our methods. First, our follow-up periods were short, varying from an average of 6 months (cohort 4) to 3.5 years (cohort 1 ). Process outcomes may have occurred 
after the end of follow-up, particularly in the case of new treatments that may have required further appointments and monitoring (eg, for new prescriptions of antihypertensives). In addition, we were unable to observe clinically important outcomes, such as incident CVD. For every 100 people invited for an HC in 2012/2013, an extra one person was prescribed a statin. Based on a literature-reported number needed to treat (NNT) for primary prevention of cardiovascular events, ${ }^{29}$ one event may be prevented for every 560 people invited for an HC, but this estimation does not account for duration of treatment or adherence. Improving NNTs would require greater uptake of the $\mathrm{HC}$ and/or greater prescribing among those with identified CVD risk. A second limitation of our study was that we were missing all data, including at baseline, for an unknown number of patients who died during the follow-up, which was a consequence of how our data source, the HHRA, was organised. These deaths will selectively have reduced numbers of those at highest risk from our population. They will tend to have been in poorer and higher risk groups, and therefore less likely to attend an HC. The numbers would have been balanced between the cohorts, so should not have affected our between-cohort comparisons. However, they might have reduced the overall risk profile, and differentially within cohorts favour attendance. A third limitation was contamination bias, as some patients in the uninvited group attended an HC. Contamination was largely inevitable given advertising and public awareness of the $\mathrm{HC}$ and given that all included GPs were involved in delivering the programme. Contamination likely led to an underestimation of the effectiveness of the HC programme in our study. Fourth, we had limited details on some factors, including diet and alcohol intake, and non-medical interventions, such as lifestyle advice. Lifestyle advice may have ranged from brief general advice to individually tailored advice with subsequent follow-up. However, such variation likely had a small effect on our results given an earlier study that reported a lack of an association between the intensity of lifestyle advice as part of an $\mathrm{HC}$ and related CVD risk reduction. ${ }^{30}$ Fifth, there were potential coding errors or omissions by GPs in recording attendance, measurements, diagnoses and interventions. This may have been particularly problematic for cohort 1 because Read Codes for HC completion were only released in 2012, after the start of the invitation year. Failure of GPs to code attendance retrospectively (ie, once the Read Codes were available) may, in part, explain why there was lower recorded HC attendance in cohort 1 compared with the other cohorts. Otherwise, coding errors would have affected the intervention and non-intervention groups equally. Sixth, we missed data on HC undertaken in community pharmacies and other non-GP settings, although this was a small minority. Our population was not necessarily representative of the UK, and we had no data on ethnicity. Hampshire does comprise significant urban, suburban and rural populations, but the proportion of ethnic minorities is lower than the national average and this may limit the generalisability of our results. Seventh, we excluded around $35 \%$ of the eligible population. This was because of problems with the invitation system, missing DOBs, Read Codes not formatted according to version 2 and unknown invitation status for some participants (eg, because of moving into the study area after the start of the follow-up period). However, these exclusions would have been equal across the cohorts. Finally, our study period ended in 2015, and clinical guidance as well as engagement by GPs and patients with the HC programme may have changed since then.

In conclusion, this study evaluated the NHS HC programme and showed that participation increased year on year between 2011 and 2015. The HC programme resulted in large increases in the detection of patients with CVD risk factors, particularly raised cholesterol and 10 -year CVD risk scores $>10 \%$. There were corresponding, although smaller, increases in certain evidence-based medical therapies, most notably statins. However, rates of uptake, diagnosis and treatment were well below those expected by the Department of Health. ${ }^{5}$ Future work should focus on improving uptake, including through use of non-GP settings (eg, pharmacy and so on) ${ }^{31}$ and by better communication of the programme ${ }^{32} 33$ and invitation methods driven by behavioural insights. ${ }^{34}$ Further support is also required in decision making for patients and GPs following identification of new risk factors as part of the NHS HC, potentially including incentivisation (eg, payment by results). Finally, further studies are needed to assess the longer-term effects of the $\mathrm{HC}$ on clinical outcomes and health inequalities.

Acknowledgements The authors thank NHS South, Central and West Commissioning Support Unit and the Care and Health Information Exchange Information Governance Group for their support and for provision of access to CHIA (formerly known as HHRA) data.

Contributors The corresponding author attests that all listed authors meet the authorship criteria and that no others meeting the criteria have been omitted. $\mathrm{OK}, \mathrm{FS}, \mathrm{EW}, \mathrm{RP}$ and PR conceived and designed the study. FS performed the data acquisition from the Hampshire Health Record Database, and OK performed the data analysis. OK and FS drafted the manuscript, which was reviewed and amended by all authors. All authors, external and internal, had full access to all of the data (including statistical reports and tables) in the study and can take responsibility for the integrity of the data and the accuracy of the data analysis. PR is guarantor.

Funding The authors have not declared a specific grant for this research from any funding agency in the public, commercial or not-for-profit sectors.

Competing interests None declared.

Patient consent for publication Not required.

Ethics approval This study received ethical approval from the Research Ethics Committee at the University of Southampton (ID: 24358) and approval from the Hampshire Health Record Information Governance Group.

Provenance and peer review Not commissioned; externally peer reviewed.

Data availability statement Access to the data used in this study is administrated by the Care and Health Information Exchange (CHIE) Information Governance Group, which is managed by the South, Central and West Commissioning Support Unit on behalf of health and social care organisations in Hampshire, Farnham and the Isle of Wight.

Open access This is an open access article distributed in accordance with the Creative Commons Attribution Non Commercial (CC BY-NC 4.0) license, which permits others to distribute, remix, adapt, build upon this work non-commercially, 
and license their derivative works on different terms, provided the original work is properly cited, appropriate credit is given, any changes made indicated, and the use is non-commercial. See: http://creativecommons.org/licenses/by-nc/4.0/.

\section{REFERENCES}

1. GBD 2017 Disease and Injury Incidence and Prevalence Collaborators. . global, regional, and national incidence, prevalence, and years lived with disability for 354 diseases and injuries for 195 countries and territories, 1990-2017: a systematic analysis for. Lancet 2018;392(10159:1789-858.

2. Bhatnagar $P$, Wickramasinghe $\mathrm{K}$, Williams J, et al. The epidemiology of cardiovascular disease in the UK 2014. Heart 2015;101:1182-9.

3. Smith ER. The Canadian heart health strategy and action plan. Vol. 25, the Canadian Journal of cardiology. England 2009:451-2.

4. Frieden TR, Berwick DM. The "Million Hearts" initiative--preventing heart attacks and strokes. N Engl J Med 2011;365:e27.

5. Department of Health. Economic modelling for vascular checks. London: Department of Health, 2008.

6. Mytton OT, Jackson C, Steinacher A, et al. The current and potential health benefits of the National health service health check cardiovascular disease prevention programme in England: a microsimulation study. PLoS Med 2018;15:e1002517.

7. NHS Health Check Best practice guidance. Public health England, 2016. Available: http://www.healthcheck.nhs.uk/ [Accessed 2/12/17]

8. Krogsboll LT, Jorgensen KJ, Gotzsche PC. Universal health checks should be abandoned. BMJ (Clinical research ed)England, 2013: 347. f5227.

9. Capewell S, McCartney M, Holland W. Nhs health Checks-a naked emperor? J Public Health 2015;37:187-92.

10. Krogsbøll LT, Jørgensen KJ, Grønhøj Larsen C, et al. General health checks in adults for reducing morbidity and mortality from disease. Cochrane Database Syst Rev 2012;10.

11. Dalton ARH, Bottle A, Okoro C, et al. Uptake of the NHS health checks programme in a deprived, culturally diverse setting: crosssectional study. J Public Health 2011;33:422-9.

12. Nicholas JM, Burgess $\mathrm{C}$, Dodhia $\mathrm{H}$, et al. Variations in the organization and delivery of the 'NHS health check' in primary care. $J$ Public Health 2013;35:85-91.

13. Jenkinson CE, Asprey A, Clark CE, et al. Patients' willingness to attend the NHS cardiovascular health checks in primary care: a qualitative interview study. BMC Fam Pract 2015;16:33.

14. Waterall J, Greaves F, Gresser C, et al. Response to Capewell et al. J Public Health 2015;37:193-4.

15. Martin A, Saunders CL, Harte E, et al. Delivery and impact of the NHS health check in the first 8 years: a systematic review. $\mathrm{Br} J \mathrm{Gen}$ Pract 2018;68:e449-59.

16. Robson J, Dostal I, Sheikh A, et al. The NHS Health Check in England: an evaluation of the first 4 years. BMJ Open 2016;6:e008840.

17. Forster AS, Burgess C, Dodhia H, et al. Do health checks improve risk factor detection in primary care? matched cohort study using electronic health records. J Public Health 2016;38:552-9.

18. Artac M, Dalton ARH, Majeed A, et al. Effectiveness of a national cardiovascular disease risk assessment program (NHS health check): results after one year. Prev Med 2013;57:129-34.
19. Lefebvre C, Manheimer E, Glanville J. Box 6.3.a: Cochrane definitions and criteria for randomized controlled trials (RCTs) and controlled clinical trials (CCTs). In: Higgins JPT, Green S, eds. Cochrane Handbook for systematic reviews of interventions.

20. R Development Core Team. R: a language and environment for statistical computing. R Foundation for Statistical computing, Vienna, Austria. ISBN 3-900051-07-0, 2008. Available: http://www.R-project. org

21. Collins R, Reith C, Emberson J, et al. Interpretation of the evidence for the efficacy and safety of statin therapy. The Lancet 2016;388:2532-61.

22. Robson J, Dostal I, Madurasinghe V, et al. The NHS health check programme: implementation in East London 2009-2011. BMJ Open 2015;5:e007578.

23. Araneta MR, Kanaya A, Fujimoto W, et al. Optimum BMI cut-points to screen Asian Americans for type 2 diabetes. poster presentation at American diabetes association 74th scientific sessions, 13-17 June. San Francisco, CA, 2014.

24. NICE guidelines [CG127]. Available: https://www.nice.org.uk/ guidance/cg127 [Accessed 16 Mar 2018].

25. Gulliford MC, Khoshaba B, McDermott L, et al. Cardiovascular risk at health checks performed opportunistically or following an invitation letter. cohort study. J Public Health 2018;40:e151-6.

26. Chang KC-M, Soljak M, Lee JT, et al. Coverage of a national cardiovascular risk assessment and management programme (NHS health check): retrospective database study. Prev Med 2015;78:1-8.

27. Cochrane T, Gidlow CJ, Kumar J, et al. Cross-Sectional review of the response and treatment uptake from the NHS health checks programme in Stoke on Trent. J Public Health 2013;35:92-8.

28. Smith S, Waterall J, Burden ACF. An evaluation of the performance of the NHS health check programme in identifying people at high risk of developing type 2 diabetes. BMJ Open 2013;3:e002219.

29. Taylor F, Huffman MD, Macedo AF. Statins for the primary prevention of cardiovascular disease. In:Huffman MD, editor. Cochrane Database of Systematic Reviews [Internet]. Chichester, UK: John Wiley \&Sons, Ltd, 2013: cited 2017 Dec 3. http://doi. wiley.com/10.1002/14651858. CD004816.pub5

30. Cochrane T, Davey R, lqbal Z, et al. Nhs health checks through general practice: randomised trial of population cardiovascular risk reduction. BMC Public Health . 2012;12:944 http://bmcpublichealth. biomedcentral.com/articles/

31. Woringer M, Cecil E, Watt $\mathrm{H}$, et al. Evaluation of community provision of a preventive cardiovascular programme - the National Health Service Health Check in reaching the under-served groups by primary care in England: cross sectional observational study. BMC Health Serv Res 2017;17:405.

32. Usher-Smith JA, Harte E, MacLure C, et al. Patient experience of NHS health checks: a systematic review and qualitative synthesis. BMJ Open 2017;7:e017169.

33. Riley R, Coghill N, Montgomery A, et al. Experiences of patients and healthcare professionals of NHS cardiovascular health checks: a qualitative study. J Public Health 2016;38:543-51.

34. Sallis A, Bunten A, Bonus A, et al. The effectiveness of an enhanced invitation letter on uptake of national health service health checks in primary care: a pragmatic quasi-randomised controlled trial. BMC Fam Pract 2016;17:35. 